Review article

\title{
A monograph on Perampanel
}

\author{
Somasundaram Aadhimoolam Chinnadurai a,*, Lakshmi Narasimhan Ranganathan ${ }^{\text {a }}$, \\ Gobinathan Shankar ${ }^{a}$, Tamilpavai Arulnambi ${ }^{a}$, Man Mohan Mehndiratta ${ }^{\mathrm{b}}$ \\ a Institute of Neurology, Madras Medical College, Chennai, India \\ bJanakpuri Superspeciality Hospital, New Delhi, India
}

\section{A R T I C L E IN F O}

\section{Article history:}

Received 10 June 2016

Accepted 17 August 2016

Available online 29 August 2016

\section{Keywords:}

Adjunctive therapy

AMPA antagonist

Focal epilepsy

\begin{abstract}
A B S T R A C T
Perampanel is a non-competitive antagonist at the AMPA (alpha-amino-3-hydroxy-5-methyl-4isoxazoleproprionic acid) subtype of ionotropic glutamate receptor. It is approved as an adjunctive therapy in focal epilepsy with or without secondarily generalised seizures in patients aged $>12$ years. This in-depth review describes the structure, mechanism of action, pharmacokinetic profile, indications, dosage and efficacy, contraindications, possible drug interactions, adverse effect profile and its management with regards to Perampanel. It is one of the latest additions in the therapeutic armamentarium of an epileptologist being useful in focal as well as generalised epilepsies as an add-on. It has shown high rates of efficacy and a relatively good tolerability. Slow dose titration, patient education and bed time dosing along with downtitration of medications which may aggravate Perampanel associated adverse events improves the patients' compliance and quality of life.

(c) 2016 Published by Elsevier, a division of RELX India, Pvt. Ltd on behalf of Indian Epilepsy Society.
\end{abstract}

\section{Introduction}

15 new compounds have been introduced into the antiepileptic armoury over the past two decades. ${ }^{1}$ Notwithstanding this development, focal seizures remain uncontrolled in more than $30 \%$ of the cases. ${ }^{2}$ Focal seizures are notorious for their tendency to remain uncontrollable despite treatment, thus making a combination therapy in such cases essential. On the flip side however, is the ever-increasing concern regarding adverse effects and neurotoxicity of polypharmacy - especially when using a combination of drugs with a similar mode of attack. ${ }^{3}$ Hence, newer drugs with novel modes of action are the need of the hour to improve seizures control without augmenting the pre-existing probability of adverse events. Clinical trials which are essential for introduction of any drug into the routine clinical practice, may not reflect the day to day usage by a clinician, making it essential for everyone to understand the efficacy and safety profile of individual drugs. ${ }^{4-7}$

Conventionally, N-methyl-D-Aspartate (NMDA) was the prime target of interest for reducing neuronal excitability due to its key role in synaptic potentiation. But it was later discovered that normally functioning NMDA receptors were essential for vital higher processes like formation of memory. Memory deficits and

\footnotetext{
* Corresponding author at: No. 64, N Block, Agathiyar Nagar, Villivakkam, Chennai 600049, India.

E-mail address: neurosoman@gmail.com (S.A. Chinnadurai).
}

learning disabilities may be side effects of NMDA antagonism. ${ }^{8,9}$ Hence, newer drugs which target non-NMDA receptors may have better acceptability.

Perampanel or chemically 2-(2-oxo-1-phenyl-5-pyridin-2-yl1,2-dihydropyridin-3-yl) benzonitrile hydrate (4:3) with a molecular formula C23.H15.N3O $3 / 4 \mathrm{H}_{2} \mathrm{O}$ (molecular mass 362.90 ) (Fig. 1) acts through selective non-competitive antagonism of AMPA (alpha-amino-3-hydroxy-5-methyl-4-isoxazoleproprionic acid) which is a major subtype of the ionotropic glutamate receptors. Three pivotal clinical trials found Perampanel to be effective in refractory partial onset seizures. ${ }^{10,12}$ It has also been approved as an adjunct for primary generalised tonic clonic seizures (GTCS). Dizziness, somnolence, and fatigue are the major dose related side effects. FDA approval was given for its usage in partial and primary generalised tonic clonic seizures for patients who are older than 12 years of age.

\section{Mechanism of action}

AMPA receptors post-synaptically mediate excitatory neurotransmission of glutamate and thus play a crucial role in epileptogenesis. Glutamate, once released pre-synaptically binds to the AMPA receptors in the post-synaptic neurons and opens several cation channels causing post-synaptic depolarisations called excitatory post-synaptic potentials (EPSPs) (Fig. 2).

Spatial or temporal summation of these potentials on reaching the threshold, trigger an action potential in these neurons thus 


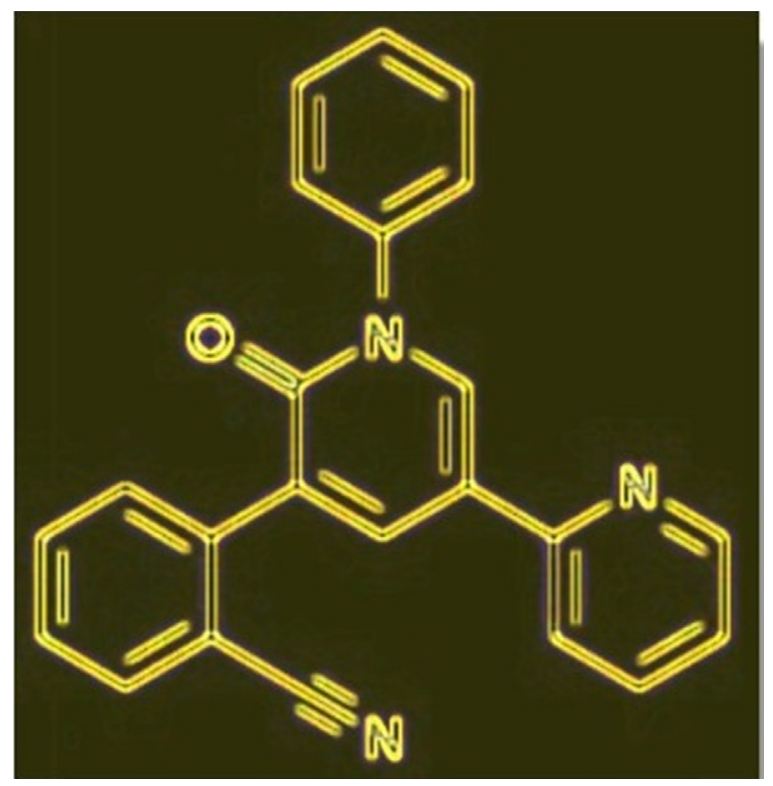

Fig. 1. Structure of Perampanel.

completing the information transfer to the post-synaptic neurons. Thus, Perampanel by acting as a non-competitive negative allosteric antagonist (Fig. 3) at these AMPA receptors reduce post-synaptic neuronal excitability and thereby increases the seizure threshold. ${ }^{13}$ Being a selective antagonist, other glutamate receptors-NMDA (N-methyl-D-aspartate) and kainate are unaffected. ${ }^{14}$

\section{Pharmacokinetics}

Route of administration is oral with a rapid and complete absorption. Rate of absorption may decline with food. $C_{\max }$ decreased by $28-40 \%$ and $T_{\max }$ delayed by $2-3 \mathrm{~h}$ with food (Fig. 4). First pass metabolism is negligible. The area under the curve (AUC, implying the extent of drug absorption) shows a dose proportional increase after single and multiple doses.

The terminal half-life of Perampanel is $105 \mathrm{~h}$ and hence the steady state is attained in $2-3$ weeks. It is $95 \%$ bound to albumin and alpha 1-acid glycoprotein. Blood to plasma ratio of perampanel is 0.55-0.59. Compared to Talampanel, another AMPA receptor antagonist, the longer half-life of Perampanel allows once a day dosage. A clearance rate of $12 \mathrm{ml} / \mathrm{min}(0.72 \mathrm{l} / \mathrm{h})$ was observed in healthy subjects. Though no gender based dosage adjustment is required, the clearance rate of Perampanel was $18 \%$ lower in females when compared to males. It is metabolised primarily through CYP3A4 and CYP3A5 and to a lesser by CYP1A2 and CYP2B6. Hence plasma levels decline to $50-67 \%$ with concomitant use of known CYP inducers. $48 \%$ is excreted in faeces and $22 \%$ in urine as a mixture of oxidative and conjugated metabolites.

In patients with hepatic impairment, plasma drug levels were $50 \%$ higher in patients with mild hepatic impairment (Child - Pugh A). An increase of $225 \%$ occurs in patients with a moderate

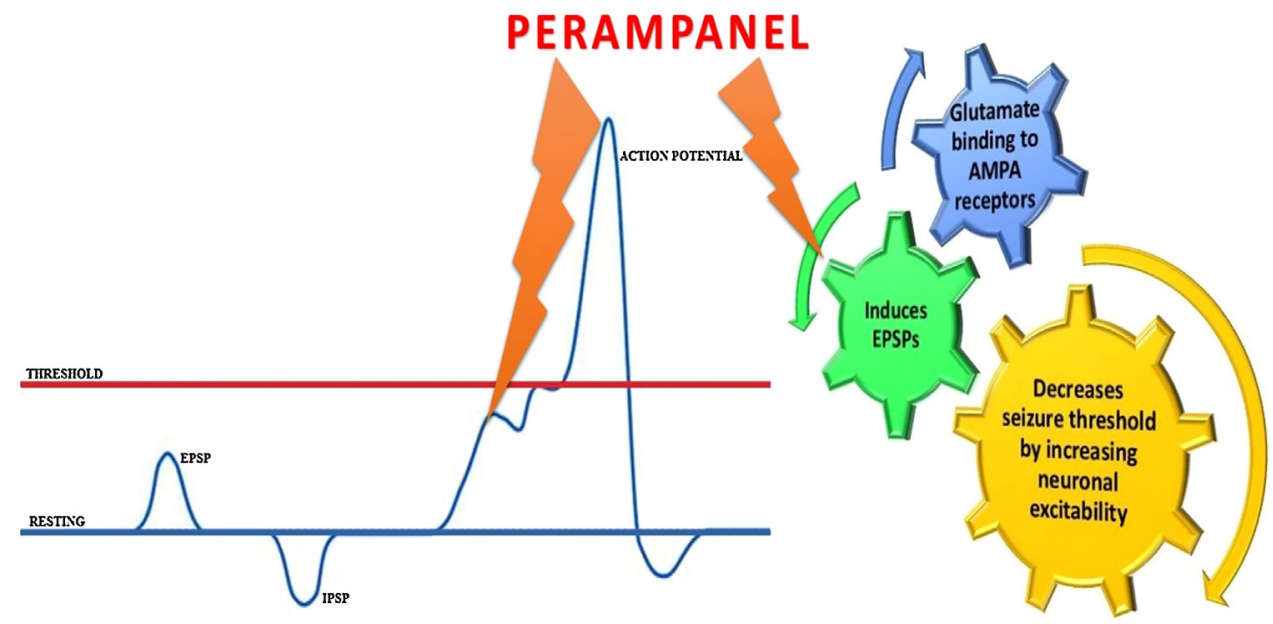

Fig. 2. Mechanism of action.

\section{Competitive vs non-competitive antagonism}

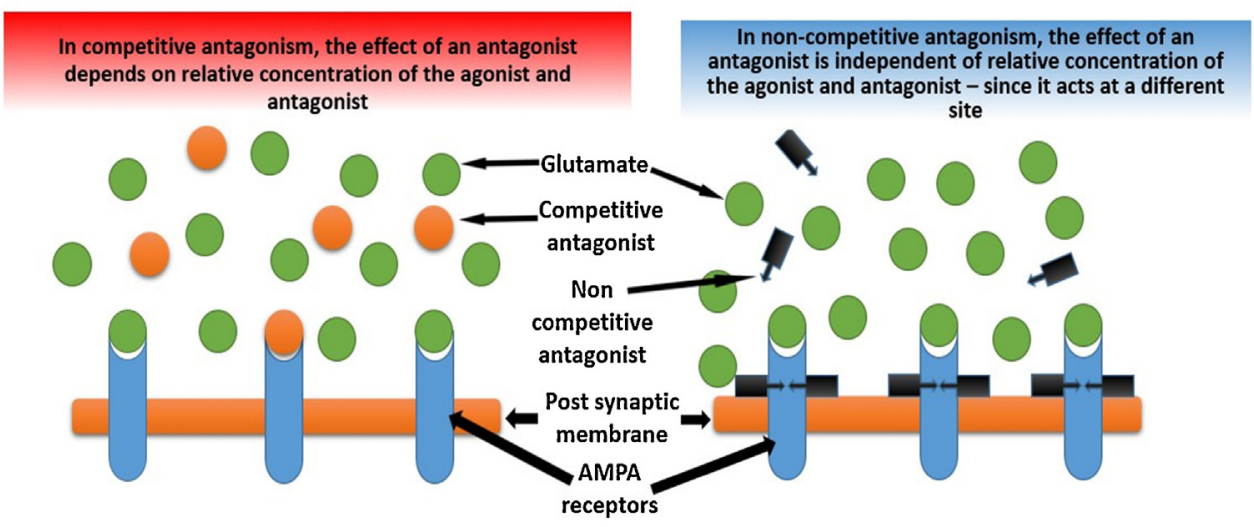

Fig. 3. Competitive vs non-competitive antagonism. 


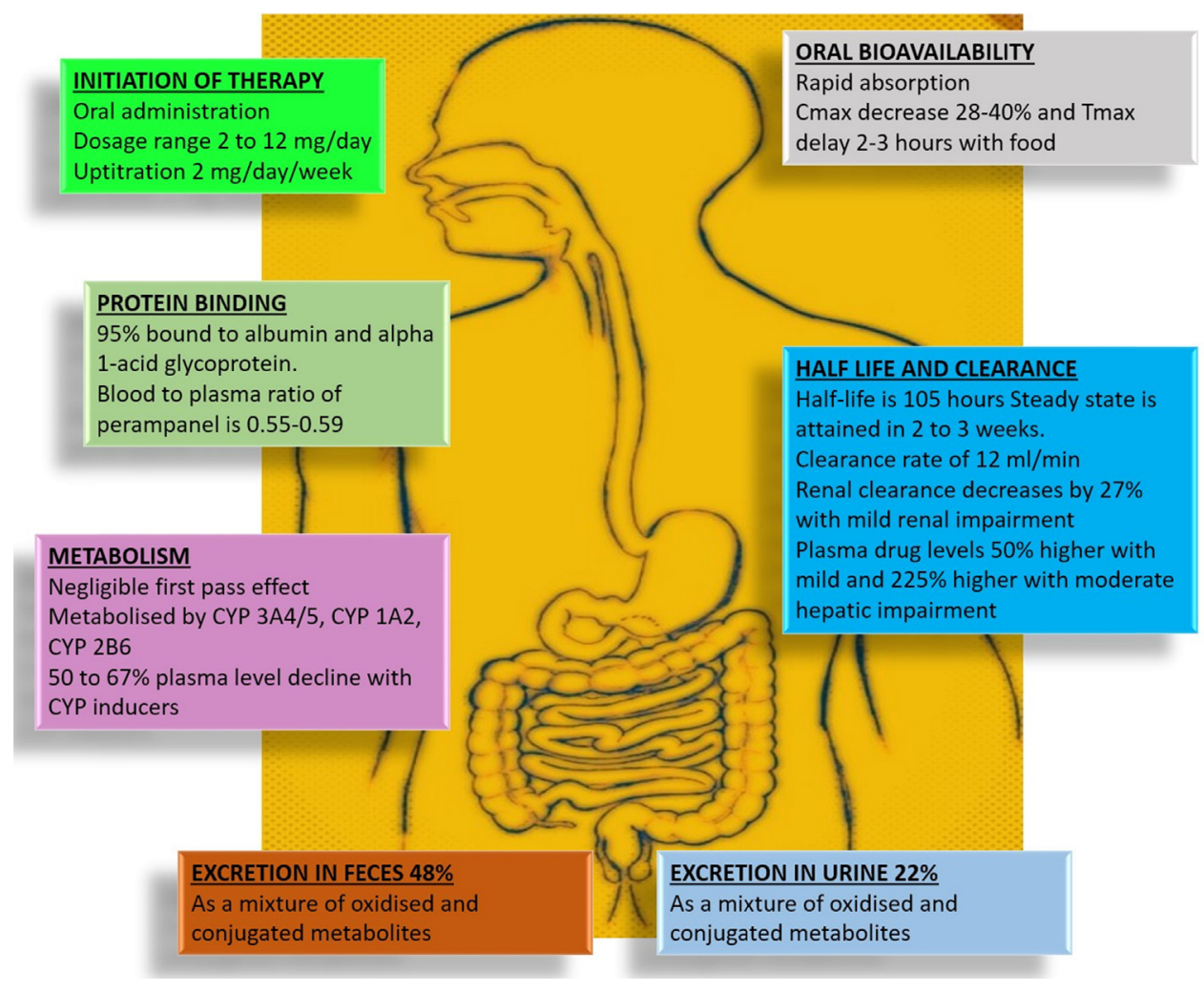

Fig. 4. Pharmacokinetics of Perampanel.

impairment (Child - Pugh B) compared to healthy controls. Halflife also significantly increases with hepatic impairment.

With mild renal impairment, the renal clearance of Perampanel decreases by $27 \%$ with a $37 \%$ increase in the AUC.

\section{Indications, dosage, and efficacy}

Major indications are partial seizures and GTCS. ${ }^{15}$ When used concomitantly with enzyme inducing antiepileptic drugs (AEDs) in individuals $\geq 12$ years of age like carbamazepine, oxcarbazepine, phenobarbitone, and phenytoin, an initial dosage of $4 \mathrm{mg}$ orally at bed time titrated at a rate of $2 \mathrm{mg} / \mathrm{day} /$ week depending on the clinical response and tolerance. Dose titration in the elderly should be done at biweekly or longer intervals only. The dosage range is 4$12 \mathrm{mg} /$ day. Withdrawal of the co-administered enzyme inducing AED warrants dosage reduction.

In patients who do not take another enzyme inducing AED, the starting dose is $2 \mathrm{mg}$ PO, with a $2 \mathrm{mg} /$ day/week increment until the desired target is achieved with a recommended maintenance dose of $8 \mathrm{mg} /$ day. $12 \mathrm{mg} /$ day PO is considered as the dosage limit. For individuals less than 12 years of age, its efficacy and safety profile have not been established.

In patients with a mild/moderate hepatic impairment, initial dosage is $2 \mathrm{mg} /$ day PO increased by $2 \mathrm{mg}$ every two weeks when desired to a maximum dose of $6 \mathrm{mg} /$ day in mild impairment and $4 \mathrm{mg} /$ day in moderate impairment. No dosage adjustment is necessary for mild/moderate renal impairment, though the dosage titration should be more gradual. Perampanel is not recommended in severe hepatic or renal impairment. Renal and liver function test must be monitored periodically during the course.

Perampanel was evaluated for its efficacy in three major trials as mentioned previously. ${ }^{10,12}$ The final pooled data from these pivotal trials is illustrated in Table 1 . The patients in these trials were all 12 years of age or older and were experiencing partial seizures with or without secondary generalisation with treatment with up to three antiepileptic drugs. As we can see, the addition of Perampanel did reduce the frequency of partial seizures and secondary generalised seizures with an increasing efficacy with increasing dosage up to $8 \mathrm{mg}$. The rate of adverse events was 77\% with the Perampanel group and $66.5 \%$ with the control group. Major symptoms were giddiness, fatigue and somnolence. Drug withdrawal rates were $4.8 \%, 3 \%, 8 \%$, and $19 \%$ in the placebo, $4 \mathrm{mg}, 8 \mathrm{mg}$, and $12 \mathrm{mg}$ groups, respectively. Seizure responses were maintained over a 3 years of follow up particularly in the secondary generalised seizure group in an open label extension study. ${ }^{16}$

A systematic review by Khan et al. found the efficacy of Perampanel to be comparable with that of Eslicarbazepine, Lacosamide, and Retigabine. ${ }^{17}$

Table 1

Pooled data from three phase III trials with Perampanel.

\begin{tabular}{|c|c|c|c|c|}
\hline & Placebo & $4 \mathrm{mg}$ & $8 \mathrm{mg}$ & $12 \mathrm{mg}$ \\
\hline Number of patients & 442 & 172 & 431 & 255 \\
\hline Baseline frequency of partial seizures per month & 11.1 & 10 & 12.2 & 13 \\
\hline Median change in partial seizure frequency with Perampanel & $-12.8 \%$ & $-23.3 \%$ & $-28.8 \%$ & $-27.2 \%$ \\
\hline Baseline frequency of secondary generalised seizures per month & 3.7 & 3.7 & 3.4 & 4.1 \\
\hline Median change in secondary generalised seizure frequency with Perampanel & $-19.4 \%$ & $-48.6 \%$ & $-62.9 \%$ & $-53.3 \%$ \\
\hline Proportion of patients to become seizure free with Perampanel & $1 \%$ & $4.3 \%$ & $3.3 \%$ & $3.7 \%$ \\
\hline Proportion of patients with more than $50 \%$ reduction in frequency of partial seizures & $19.3 \%$ & $28.5 \%$ & $35.3 \%$ & $35 \%$ \\
\hline
\end{tabular}




\section{Contraindications}

The following are the list of circumstances in which the usage of Perampanel may be harmful.

- Pregnancy - falling under category $C$, animal data suggest that Perampanel may cause foetal harm like decreased weight, visceral abnormalities, delayed sexual maturation and foetal demise. Not much human data is available at present.

- Breast-feeding - caution is required since no data is available regarding its secretion in breastmilk.

- Driving, operating machinery - all skills which depend on the level of alertness like driving are not advisable with Perampanel usage. Somnolence, giddiness, fatigue, vertigo, gait difficulties are all adverse effects documented with Perampanel. Car handling ability was impaired at a dose of $12 \mathrm{mg}$ though single and multiple doses of $4 \mathrm{mg}$ of Perampanel does not impair driving, simple psychomotor tasks or coordination. At least 2 weeks are necessary for these events to wear off after discontinuation.

- Geriatric ( $>65$ years) and Paediatric ( $<18$ years) age - limited information only is available regarding the safety of Perampanel in the extremes of age.

- Severe hepatic disease.

- Advanced renal failure.

- Psychosis, bipolar disorder, schizophrenia - behavioural and psychiatric adverse events are associated with Perampanel. Preexistent psychosis or aggression, previous history of schizophreniform disorders, bipolar disorder, or delusional disorder warrants great caution. Anger outbursts, agitation, aggression, labile affect, irritability, hostility, and homicidal tendency have all been observed with Perampanel, which seem to be dose related. Patients and caregivers should be thoroughly counselled before a prescription in such circumstances. Close monitoring and follow-up and discontinuation if these events occur are highly recommended strategies to a prescribing practitioner.

- Coexistent substance abuse - Perampanel is a controlled substance and its usage may cause physical and psychological dependence, which warrants extreme caution in patients with a previous history of any substance abuse. Doses of 24-36 mg produces euphoria similar to some recreational drugs. Sensations of floating, detachment and other dissociative phenomenon similar to ketamine and alprazolam abuse were also noted at these high dosages of Perampanel.

- Suicidal ideation, depression - antiepileptic drugs in general, increase the risk of suicidal ideation and behaviour in patients. Risk of suicide in patients taking AEDs is twice that of the general population irrespective of the indication, the class of drug or the age of the individual. Hence, close monitoring and periodic psychiatric evaluation is indicated.

\section{Drug interactions}

Oral or implant oral contraceptives such as levonorgestrel, estradiol, ethinyl estradiol used in various combinations lose their efficacy with concomitant Perampanel use. The $C_{\max }$ and AUC of levonorgestrel were reduced by 42 and $40 \%$ respectively with a $12 \mathrm{mg} /$ day dosing of Perampanel for 3 consecutive weeks. The $C_{\max }$ of ethinyl estradiol decreased by $18 \%$ without any change in the AUC. Lower dosages of Perampanel had no effect on the $C_{\max }$ or AUC of either levonorgestrel or ethinyl estradiol.

Being a CNS depressant Perampanel may have a synergistic effect with other CNS depressants like alcohol and benzodiazepines further decreasing alertness with increased clouding of mentation, confusion, anger, irritability, recklessness, etc. Driving in such a situation could prove harmful.

Overall CYP3A4 inducers like Carbamazepine accelerate the clearance of Perampanel. $300 \mathrm{mg}$ bd dosage of carbamazepine reduced $C_{\max }$ and AUC of Perampanel by $26 \%$ and $67 \%$, respectively. The half-life declined from $56.8 \mathrm{~h}$ to $25 \mathrm{~h}$. Other CYP3A4 inducers like oxcarbazepine and phenytoin halve the AUC of Perampanel. Phenobarbitone or primidone also decrease Perampanel concentrations. Topiramate decreased the AUC of Perampanel by $20 \%$. Perampanel, a weak CYP3A4 inducer by itself also accelerates the clearance of drugs which use this route.

Inhibitors of CYP3A4 like ketoconazole at a dose of $400 \mathrm{mg} / \mathrm{day}$ for 8 days increased the half-life of Perampanel from 58.4 to $67.8 \mathrm{~h}$. Other inhibitors of CYP3A4 like itraconazole, posaconazole, or voriconazole also have a similar effect.

Rifampin, rifabutine and rifapentine induce metabolism of Perampanel and increase its clearance. Similar interaction is noted with St John's wort which is also a CYP3A4 inducer.

\section{Adverse effect profile and management}

The adverse effect profile of Perampanel is predictable and relatively acceptable and are usually only of mild to moderate intensity. ${ }^{10,11,18}$ Table 2 lists pooled incidence rates of adverse reactions occurring in $\geq 5 \%$ patients across the Perampanel phase III trials.

Dizziness, one of the most common side effects with Perampanel usually occurs when escalating the dosage or at high doses and tends to decrease with time. Hence, due to this dose dependency is classified as the classic type A adverse effect. Veterans Administration Affair Monotherapy study showed that $44-68 \%$ of the patients failed treatment almost exclusively because of dizziness, sedation, and incoordination. ${ }^{19,20}$ An individualised effort is necessary to tackle dizziness. Patient related factors like age, impaired vision and hearing, pre-existent peripheral and central nervous system pathologies, etc. come into play. Antihypertensives and diuretics when co-administered, especially in the elderly aggravate dizziness.

Table 2

Adverse reactions with Perampanel - pooled data from trials.

\begin{tabular}{|c|c|c|c|c|c|}
\hline Adverse effect & Placebo $(n=442)$ & $2 \mathrm{mg}(n=180)$ & $4 \mathrm{mg}(n=172)$ & $8 \mathrm{mg}(n=431)$ & $12 \mathrm{mg}(n=255)$ \\
\hline Any one adverse effect & $294(66.5)$ & $111(61.7)$ & $111(64.5)$ & $350(81.2)$ & $227(89.0)$ \\
\hline Dizziness & $40(9.0)$ & $18(10.0)$ & $28(16.3)$ & $137(31.8)$ & $109(42.7)$ \\
\hline Somnolence & $32(7.2)$ & $22(12.2)$ & $16(9.3)$ & $67(15.5)$ & $45(17.6)$ \\
\hline Headache & $50(11.3)$ & $16(8.9)$ & $19(11.0)$ & $49(11.4)$ & $34(13.3)$ \\
\hline Fatigue & $21(4.8)$ & $8(4.4)$ & $13(7.6)$ & $36(8.4)$ & $31(12.2)$ \\
\hline Irritability & $13(2.9)$ & $7(3.9)$ & $7(4.1)$ & $29(6.7)$ & $30(11.8)$ \\
\hline Nausea & $20(4.5)$ & $4(2.2)$ & $5(2.9)$ & $25(5.8)$ & $20(7.8)$ \\
\hline Falls & $15(3.4)$ & $2(1.1)$ & $3(1.7)$ & $22(5.1)$ & $26(10.2)$ \\
\hline Nasopharyngitis & $18(4.1)$ & $7(3.9)$ & $9(5.2)$ & $23(5.3)$ & $11(4.3)$ \\
\hline Upper respiratory tract infection & $12(2.7)$ & $11(6.1)$ & $6(3.5)$ & $14(3.2)$ & $10(3.9)$ \\
\hline Ataxia & $0(0.0)$ & $0(0.0)$ & $1(0.6)$ & $14(3.2)$ & $21(8.2)$ \\
\hline Balance disorder & $2(0.5)$ & $0(0.0)$ & $0(0.0)$ & $22(5.1)$ & $8(3.1)$ \\
\hline
\end{tabular}


A concomitant dose reduction of such drugs may be warranted if permissible. Moreover, such patients must be advised to take Perampanel dose just before retiring to bed.

Aggression is another common adverse effect of Perampanel. Hostility, anger and aggression have all been associated with Perampanel especially at a high dose. Co-administration of drugs like Levetiracetam which encourage feelings of anger towards others must be avoided in all possible situations. Patients and their relatives must be educated regarding this possible adverse effect before initiating treatment.

Falls are also common with Perampanel especially with coexistent fatigue, imbalance and hypersomnolence which are also side effects of Perampanel. Falls may be particularly troubling in the frail and elderly who are very vulnerable to fall related morbidities. Appropriate patient education and if possible, avoidance or withdrawal in such individuals may be mandatory. Bedtime dosing should be advised in all vulnerable individuals on Perampanel.

Intentional Overdosage of Perampanel has been published in a 34-year-old female German patient who ingested $204 \mathrm{mg}$ (25.5 times the daily dosage) at once in an attempt to commit suicide. Dysarthria, diminished deep tendon reflexes, confusion and anxiety were evident. Electroencephalogram showed generalised slowing without any epileptiform discharges. No other laboratory anomalies occurred. In such cases, due to rapid absorption of Perampanel from the GIT, lavage is often futile and hence supportive treatment is all that is required.

\section{Conclusion}

Thus Perampanel is one of the latest additions in the therapeutic armamentarium of an epileptologist being useful in focal as well as generalised epilepsies as an add-on. It has shown high rates of efficacy and a relatively good tolerability. Slow dose titration, patient education and bed time dosing along with downtitration of medications which may aggravate Perampanel associated adverse events improves patients' compliance and quality of life.

\section{Conflicts of interest}

The authors have none to declare.

\section{References}

1. Rheims S, Rylvin P. Profile of perampanel and its potential in the treatment of partial onset seizures. Neuropsychiatr Dis Treat. 2013;9:629-637.

2. Kwan P, Schachter SC, Brodie MJ. Drug-resistant epilepsy. $N$ Engl J Med. 2011;365:919-926

3. Stephen LJ, Brodie MJ. Antiepileptic drug monotherapy versus polytherapy: pursuing seizure freedom and tolerability in adults. Curr Opin Neurol. 2012;25:164-172.

4. Faught E. Antiepileptic drug trials: the view from the clinic. Epileptic Disord. 2012;14:114-123.

5. Marson AG, Williamson PR. Interpreting regulatory trials in epilepsy. Curr Opin Neurol. 2009;22:167-173.

6. Brodie MJ. Meta-analyses of antiepileptic drugs for refractory partial (focal) epilepsy: an observation. Br J Clin Pharmacol. 2013;76:630-631.

7. Brodie MJ, Kelly K, Stephen LJ. Prospective audits with newer antiepileptic drugs in focal epilepsy: insights into population responses? Epilepsy Behav. 2014;31:73-76.

8. Wedzony K, Fijal K, Mackowiak M, Chocyk A, Zajaczkowski W. Impact of postnatal blockade of N-methyl-D-aspartate receptors on rat behavior: a search for a new developmental model of schizophrenia. Neuroscience. 2008;153(4):1370-1379.

9. Nabeshima T, Mouri A, Murai R, Noda Y. Animal model of schizophrenia: dysfunction of NMDA receptor-signaling in mice following withdrawal from repeated administration of phencyclidine. Ann N Y Acad Sci. 2006;1086:160-168.

10. French JA, Krauss GL, Biton V, et al. Adjunctive perampanel for refractory partialonset seizures: randomized phase III study 304. Neurology. 2012;79(6):589-596.

11. Krauss GL, Serratosa JM, Villanueva V, et al. Randomized phase III study 306 : adjunctive perampanel for refractory partial-onset seizures. Neurology. 2012;78(18):1408-1415.

12. Steinhoff BJ, Ben-Menachem E, Ryvlin P, et al. Efficacy and safety of adjunctive perampanel for the treatment of refractory partial seizures: a pooled analysis of three phase III studies. Epilepsia. 2013;54:1481-1489.

13. Chen C-Y, Matt L, Hell JW, Rogawski MA. Perampanel inhibition of AMPA receptor currents in cultured hippocampal neurons. PLOS ONE. 2014;9(9):e108021. http:// dx.doi.org/10.1371/journal.pone.0108021.

14. Hanada T, Hashizume Y, Takenaka O, et al. Perampanel: a novel, orally active, noncompetitive AMPA-receptor antagonist that reduces seizure activity in rodent models of epilepsy. Epilepsia. 2011;52(July (7)):1331-1340.

15. Krauss GL, Perucca E, Ben-Menachem E, et al. Perampanel, a selective, noncompetitive $\alpha$-amino-3-hydroxy-5-methyl-4-isoxazolepropionic acid receptor antagonist, as adjunctive therapy for refractory partial-onset seizures: interim results from phase 3, extension study 307. Epilepsia. 2013;54(January (1)):126-134.

16. Krauss GL, Perucca E, Ben-Menachem E, Kwan P, Shih JJ, Clément JF. Longterm safety of perampanel and seizure outcomes in refractory partial-onset seizures and secondarily generalized seizures: results from phase III extension study 307. Epilepsia. 2014;55:1058-1068.

17. Khan N, Shah D, Tongbram V, Verdian L, Hawkins N. The efficacy and tolerability of perampanel and other recently approved anti-epileptic drugs for the treatment of refractory partial onset seizure: a systematic review and Bayesian network metaanalysis. Curr Med Res Opin. 2013;29:1001-1013.

18. Ettinger A, Lopresti A, Yang H, et al. Psychiatric and behavioural adverse events in randomized clinical studies of the noncompetitive AMPA receptor antagonist perampanel. Epilepsia. 2015;56:1252-1263.

19. Steinhoff BJ, Laurenza A, Yang H, Satlin A. Safety profile of perampanel as an adjunctive treatment for partial onset seizures. J Symptoms Signs. 2014;3:64-70.

20. Sirven JI, Fife TD, Wingerchuk DM, Drazkowski JF. Second-generation antiepileptic drugs' impact on balance: a meta-analysis. Mayo Clin Proc. 2007;82:40-47. 